\title{
DINÂMICA DE DISTRIBUIÇÃO DE FONTES DE CAPITAIS CIENTÍFICOS ENTRE DOCENTES / PESQUISADORES DE UM PROGRAMA DE PÓS-GRADUAÇÃO STRICTO-SENSU DE UMA UNIVERSIDADE PÚBLICA
}

\author{
Juliana Cristina Teixeira* \\ PÂmella Gabriela Oliveira** \\ Nathália Vasconcelos Tavares*** \\ Alexandre de PÁdua Carrieri**** \\ Mônica Carvalho Alves Cappelle******
}

Recebido: 29 jul. 2011

Aprovado: 29 ago. 2011

\begin{abstract}
*Doutoranda em Administração pelo Centro de Pós-Graduação e Pesquisas em Administração (CEPEAD) da Universidade Federal de Minas Gerais. Mestre em Administração pela Universidade Federal de Lavras. Membro do Núcleo de Estudos Organizacionais e Sociedade (NEOS) e do Grupo de Estudos em Redes, Estratégia e Inovação (GEREI-UFLA), Belo Horizonte, MG, Brasil. E-mail: julianacteixeira@yahoo.com.br **Mestre em Administração pela Universidade Federal de Lavras. Membro do Grupo de Estudos em Redes, Estratégia e Inovação (GEREI-UFLA). Professora da Fundação Educacional de Divinópolis (FUNEDI/ UEMG),. E-mail: pamellagabi@yahoo.com.br

***Mestranda em Administração pela Universidade Federal de Lavras. Membro do Grupo de Estudos em Redes, Estratégia e Inovação (GEREI-UFLA). Professora da Faculdade Adventista de Ensino de Minas Gerais (FADMINAS), Lavras, MG, Brasil. E-mail: nathaliavt2006@yahoo.com.br

****Doutor em Administração pela Universidade Federal de Minas Gerais. Líder do Núcleo de Estudos Organizacionais e Sociedade (NEOS). Professor adjunto do Departamento de Ciências Administrativas e do Centro de Pós-Graduação e Pesquisas em Administração da UFMG, Belo Horizonte, MG, Brasil. E-mail: alexandre@face.ufmg.br

*****Doutora em Administração pela Universidade Federal de Minas Gerais. Professora adjunta do Departamento de Administração e Economia da UFLA. Líder do Núcleo de Estudos em Organizações, Gestão e Sociedade (NEORGS). Membro do Núcleo de Relações de Trabalho e Tecnologias de Gestão (NURTEG) e do Grupo de Gênero e Diversidade em Movimento (GEDIM), Lavras, MG, Brasil. E-mail: edmo@dae.ufla.br
\end{abstract}

Resumo: Situando-se no contexto das universidades e, mais especificamente, da pós-graduação, o presente estudo visa analisar, de forma exploratória, a dinâmica de distribuição de capitais científicos entre docentes de um programa de pós-graduação Stricto Sensu de uma universidade pública. De forma específica, como os docentes distribuem suas atividades entre aquelas que lhes permitem acumular capital científico puro (como as publicações e contribuições acadêmicas para o campo do conhecimento) e capital científico institucional (como a ocupação de cargos que lhes conferem o poder de decisão dentro do campo da ciência). Foi considerada a abordagem de Bourdieu (2003; 2004a; 2004b) relativamente ao campo científico, por esta permitir a apreensão dessa dinâmica de distribuição de capitais, que são tipos específicos de poder. A abordagem foi quantitativa e qualitativa, utilizando pesquisa documental nos currículos Lattes de vinte e três docentes participantes do referido programa, que se situa em uma cidade de Minas Gerais (Brasil), sendo da área de Ciências Sociais Aplicadas. Como principais resultados, a dinâmica demonstra (1) que os docentes ocupam, em sua maioria, posições medianas dentro da distribuição de capitais; (2) há a dificuldade de acumulação expressiva de ambos os tipos de capitais por parte de um pesquisador; (3) não houve uma polarização entre os docentes baseada em forte acumulação de um dos capitais, e fraca acumulação de outro; e (4) há maior facilidade de conversão de capital institucional em capital científico puro.

Palavras-chave: Dinâmica. Capital científico. Docentes. Programa de Pós-graduação Stricto-Sensu. 


\author{
DYNAMICS OF DISTRIBUTION OF SOURCES OF SCIENTIFIC \\ CAPITAL AMONG TEACHERS / RESEARCHERS OF A MASTER'S \\ AND DOCTORATE'S DEGREE PROGRAM OF A PUBLIC UNIVERSITY
}

\begin{abstract}
In the context of universities and more specifically, of graduate school, this study aims to analyze, in an exploratory way, the dynamics of scientific capital distribution among teachers of a Master's and Doctorate's degree program at a public university. Specifically, how teachers are distributed among those activities that allow them to accumulate pure scientific capital (such as publications and academic contributions to the field of knowledge) and institutional scientific capital (as occupying the positions that give them the power of decision within the field of science). Bourdieu's approach (2003, 2004a; 2004b) about the scientific field was considered, because it allows us to apprehend the dynamics of capital distribution, which represents specific types of power. The approach was quantitative and qualitative, using documentary research in the curriculum Lattes of twenty-three teachers participating of the program, which is located in a city in Minas Gerais (Brazil) and belongs to the area of Applied Social Sciences. As main results, the dynamics demonstrates (1) that mostly teachers occupy median positions within the distribution of capital, (2) it's difficult to accumulate both types of capital, (3) there isn't a polarization among teachers that have a strong accumulation of one kind of capital, and weak accumulation of the other capital, and (4) it's easier to convert institutional capital into pure scientific capital.
\end{abstract}

Key words: dynamics; scientific capital; teachers; Master's and Doctorate's degree program.

\title{
1 INTRODUÇÃO
}

O objetivo principal do presente artigo é analisar, de forma exploratória, a dinâmica de distribuição de capitais científicos entre docentes de um programa de pós-graduação Stricto Sensu de uma universidade pública. De forma específica, como os docentes distribuem suas atividades entre aquelas que lhes permitem acumular capital científico puro (como as publicações e contribuições acadêmicas para o campo do conhecimento) e capital científico institucional (como a ocupação de cargos que lhes conferem o poder de decisão dentro do campo da ciência).

O contexto de análise é o das universidades, que são "instituições pluridisciplinares de formação dos quadros profissionais de nível superior, de pesquisa, de extensão e de domínio e cultivo do saber humano" (BRASIL, 1996, art. 52). Oferecem regularmente atividades de ensino, pesquisa e extensão; sendo que entre as atividades de ensino estão incluídos programas de mestrado ou doutorado que devem ser positivamente avaliados pela Capes - Coordenação de Aperfeiçoamento do Pessoal de Nível Superior (BRASIL, 2001, art. $8^{\circ}$ ). São públicas quando são "criadas ou incorporadas, mantidas e administradas pelo Poder Público" e privadas quando "mantidas e administradas por pessoas físicas ou jurídicas de direito privado" (BRASIL, 2001, art. $1^{\circ}$ ).

Os docentes dessas universidades podem se envolver em atividades nas quais se relacionam diretamente com os alunos; como também em atividades 
relacionadas à gestão e administração de seus setores e departamentos. Além disso, podem atuar em cursos de nível de graduação, como também em cursos de pós-graduação Stricto ou Lato Sensu. Dessa forma, são estimulados a se dedicar a atividades de diferentes naturezas que, por sua vez, podem lhe conferir status, prestígio ou formas específicas de poder dentro das instituições que ocupam.

Tais docentes se inserem no que se pode chamar de campo científico, já que se submetem à lógica da Ciência. No presente estudo, consideraremos a abordagem de Bourdieu (2003; 2004a; 2004b) relativamente ao campo científico, por esta permitir a apreensão da dinâmica de distribuição de capitais (tipos específicos de poder) entre docentes / pesquisadores dentro do âmbito acadêmico. Considerar os diferentes capitais descritos pelo autor relativamente ao campo científico permite que se considerem as atividades de diversas naturezas que são desempenhadas dentro de um programa de pós-graduação, já que Bourdieu (2004b) defende que neste campo específico os atores podem acumular duas espécies diferentes de capitais, o capital "puro" e o capital institucional (ou político). O capital "puro" refere-se aos conhecimentos e contribuições dos mesmos para o desenvolvimento da ciência (como publicações acadêmicas, produção e disseminação de conhecimentos), e o capital institucional refere-se aos cargos que ocupam nas instituições em que atuam, que podem thes conferir um poder de caráter político e decisório (atividades de gestão, por exemplo).

$\mathrm{Na}$ dinâmica de distribuição de capitais científicos acumulados, Bourdieu (2004b) considera de difícil ocorrência, ainda, uma situação na qual os indivíduos acumulem de forma expressiva ambos os tipos de capitais. Para o autor, os extremos é que seriam comuns, ou seja, um pesquisador com forte poder político (alta acumulação de capital institucional) e fraco poder específico (fraca acumulação de capital científico puro), e a situação inversa, um pesquisador com fraco poder político e forte poder específico. Um exemplo que pode explicar esta lógica é que ocupar cargos administrativos e políticos dentro da universidade exige tempo, o que pode comprometer, por exemplo, o nível de publicação acadêmica do pesquisador, a qual garantiria ao mesmo um capital científico puro.

Nesse sentido, um objetivo específico relacionado ao objetivo principal do estudo acima descrito é analisar se os docentes / pesquisadores (do programa analisado) que ocupam mais cargos políticos possuem menos prestígio do ponto de vista de produção acadêmica e, em contrapartida, se quem possui mais prestígio acadêmico ocupa de forma menos expressiva cargos ou funções políticas.

Em termos operacionais, o estudo investigou como se deu, em um período de cinco anos, a distribuição de fontes de capital institucional e de capital cien- 
tífico puro entre 23 docentes de um programa de pós-graduação Stricto-Sensu de curso de Ciências Sociais Aplicadas de uma universidade pública brasileira. Para tal, foram considerados os currículos dos docentes disponibilizados na Plataforma Lattes, analisados por meio das regras de pontuação de currículos adotadas pelo próprio programa de pós-graduação Stricto-Sensu (em processos de seleção para ingresso nos cursos de Mestrado e Doutorado), bem como a descrição da ocupação pelos docentes de cargos relativos à gestão, com base nos dados contidos nos currículos.

Um pressuposto da pesquisa era o de que haveria uma polarização entre os docentes que acumulam mais fontes de capital institucional ou político, de um lado, e aqueles que acumulam mais fontes de capital científico puro, de outro, o que não foi observado, já que não houve uma polarização significativa. Acreditase que a pesquisa realizada demonstre não só a forma com que se distribuem as fontes de capitais científicos, como também possibilite uma reflexão acerca do modo como os docentes têm respondido à complexidade inerente ao seu papel, representada pela demanda por múltiplos focos de trabalho, divididos entre atividades de ensino, pesquisa, extensão, e também de gestão. Além disso, a contribuição do estudo reside na necessidade, apontada por Brandão (2010), de se por à prova empírica os conceitos de Pierre Bourdieu.

O artigo divide-se da seguinte forma: no segundo e terceiro itens é apresentado o referencial teórico utilizado, no qual se aponta a temática que envolve as universidades públicas brasileiras e atividades de seus docentes, e os conceitos de campo e capitais científicos de Bourdieu. No quarto, são descritos os procedimentos metodológicos. No quinto item, são descritos e analisados os resultados, seguidos então pelas considerações finais no item seis.

\section{AS UNIVERSIDADES PÚBLICAS BRASILEIRAS E AS ATIVIDADES DE SEUS DOCENTES}

As universidades públicas, enquanto instituições, possuem um caráter inerente de normas e regulamentos, já que "as instituições consistem de estruturas e atividades cognitivas, normativas e regulativas, que dão estabilidade e significado ao comportamento social" (SCOTT, 2001, p. 33). Ainda, a "instituição significa o estabelecimento de padrões de comportamento na execução de determinadas tarefas" (DUARTE JÚNIOR, 1986, p. 39). O atendimento a esses padrões confere às universidades uma posição de respeito perante a sociedade, o que faz com que a noção de legitimidade se torne importante (VICENTIN; PASSADOR, 2008) para compreender o contexto das mesmas. Entre os ele- 
mentos institucionais responsáveis pela legitimidade estão as formas culturais, como normas e leis; as estruturas sociais, tais como poder e autoridade; e as atividades cotidianas que são padronizadas por meio de pressões normativas, coercitivas ou cognitivas (SCOTT, 2001).

Dessa forma, a universidade pública, desde seu surgimento, é tida como uma instituição social, uma ação ou prática "fundada no reconhecimento público de sua legitimidade e de suas atribuições, num princípio de diferenciação, que lhe confere autonomia perante outras instituições sociais" (CHAUI, 2003, p. 5). Em sua caracterização, Sousa Santos (2005) defende que, após uma acumulação indiscriminada de funções atribuídas à universidade no século XX, muitas vezes sem uma articulação lógica, a partir do século XXI se pressuponha como universidade apenas instituições em que há a "formação graduada e pósgraduada, pesquisa e extensão". Pois, "sem qualquer destes, há ensino superior, não há universidade" (SOUSA SANTOS, 2005, p. 169).

Além disso, de acordo com Vanderley e Ximenes (2008), a universidade se caracteriza pela existência de um alto profissionalismo das tarefas (pela necessidade dos docentes por autonomia e liberdade no trabalho), descentralização na tomada de decisões, coexistência de diferentes concepções; e ambiguidade e dispersão do poder.

Inseridos nesse contexto, os docentes têm sido alvos de avaliação há décadas, desde que a Capes e o CNPq (Conselho Nacional de Desenvolvimento Científico e Tecnológico) se consolidaram como órgãos de regulação e de avaliação de programas de pós-graduação no Brasil (BARBOSA et al, 2007). A Capes é o órgão responsável por formular a Política Nacional de Pós-Graduação Stricto Sensu, atuando também como Agência Executiva do Ministério da Educação e Cultura, possuindo como principais funções a elaboração, avaliação, acompanhamento e coordenação das atividades de Pós-Graduação no Brasil (VICENTIN; PASSADOR, 2008; CAPES, 2010).

Nas avaliações empreendidas pela instituição, o corpo docente possui alta significância enquanto fator considerado, sendo o critério mais importante de seu sistema de avaliação (MACCARI et al, 2008). Como aspectos avaliados em relação ao mesmo, estão:

[...] (a) formação dos docentes permanentes; (b) adequação da dimensão, composição e dedicação dos docentes permanentes; (c) perfil do docente permanente em relação à proposta do programa; (d) atividade dos docentes permanentes na pós-graduação; (e) atividades dos docentes permanentes na graduação; e (f) participação dos docentes em pesquisa e desenvolvimento de projetos (MACCARI et al, 2008, p. 184). 
Além da submissão a estas avaliações, observa-se que transformações sociais, reformas educacionais e o aumento da demanda da população por proteção social fizeram com que o papel do docente fosse significativamente ampliado. Pois

na atualidade, o papel do docente extrapolou a mediação do processo de conhecimento do aluno, o que era comumente esperado. Ampliouse a missão profissional para além da sala de aula, a fim de garantir uma articulação entre a instituição e a comunidade. O docente, além de ensinar, deverá participar da gestão e do planejamento institucional, o que significa uma dedicação mais ampla, a qual se estende às famílias e à comunidade (VANDERLEY; XIMENES, 2008, p. 1-2).

Além disso, a participação dos docentes também na gestão e planejamento das universidades é fundamental para que a autonomia das mesmas seja concebida, já que seu processo de tomada de decisões deve ser deliberativo e, por lei, contar com a participação dos mesmos. Há, para as instituições públicas de educação superior, a necessidade de atendimento ao princípio da gestão democrática, em que $70 \%$ dos assentos em órgãos colegiados deliberativos e comissões devem ser ocupados por docentes (BRASIL, 1996, art. 56). O que não retira suas obrigações pertinentes ao ensino, já que o professor é obrigado a dar no mínimo oito horas semanais de aula (BRASIL, 1996, art. 57).

Observa-se assim a complexidade do trabalho do docente e sua permanente avaliação enquanto profissional "desde o ingresso na carreira, através de concursos, de avaliações sistemáticas para a ascensão profissional, da submissão de trabalhos em eventos, da apresentação de projetos para financiamentos e de relatórios de atividades e de pesquisa" (ROWE; BASTOS, 2008, p. 2). Nesse contexto, somam-se críticas à própria forma com que os cursos de pós-graduação têm sido avaliados, com uma atenção muito direcionada à produtividade, e não à forma com que esta é efetivada ou possível (BARBOSA et al, 2007). Pois o resultado obtido pelos programas de pós-graduação não pode se relacionar somente com variáveis quantitativas, mas também com a forma pela qual que são geridos e organizados (VICENTIN; PASSADOR, 2008). Aponta-se uma valorização da pesquisa e da publicação científica em contraposição ao ensino, pesquisa, extensão e retornos da universidade para o setor empresarial, governamental e sociedade como um todo (SPAGNOLO; SOUZA, 2004).

Acusa-se, nesse sentido, uma introdução demasiada da lógica empresarial para a lógica da universidade. Freitag (1996), por exemplo, chama atenção para o surgimento de uma universidade operacional, que seria, segundo Chaui (2003), regida por contratos de gestão, avaliada por produtividade e eficácia organizacional. Há então uma lógica empresarial imediatista, que se contrapõe 
ao médio e longo prazo inerentes à lógica da universidade. Por este motivo, se refere, inclusive no presente artigo, à "produção acadêmico-científica dos programas de pós-graduação (significando especialmente a quantidade de trabalhos publicados) e se mede a produtividade docente em número de aulas dadas" (SIMÕES, 2004, p. 129-130). Embora tal crítica não seja foco da presente discussão, corrobora para o entendimento do contexto em que se encontram os docentes de pós-graduação de uma universidade pública. A descrição das fontes de capitais científicos acumuladas pelos referidos docentes demonstra uma dinâmica de dedicação não só a atividades diretamente relacionadas ao ensino, pesquisa e extensão em si, como também à gestão e processo decisório inerentes a estes três pilares funcionais da universidade.

É nesse contexto que se insere a noção de campo científico como o espaço de uma luta concorrencial, caracterizado não somente por esta lógica de resultados a qual as universidades precisam se submeter, como também a um jogo de forças intrinsecamente presente no campo da ciência. Em sua dinâmica, os docentes, divididos entre funções pertinentes a ensino, pesquisa, extensão e gestão, acumulam capitais científicos de diferentes naturezas. E é exatamente sobre essa noção de campo e de capital científico que se discute a seguir.

\section{O CAMPO CIENTÍFICO E SEUS CAPITAIS NA VISÃO DE BOURDIEU}

Bourdieu (1996) considera a sociedade como sendo composta por vários campos diversos, ou seja, vários espaços dotados de uma autonomia relativa, com características próprias de funcionamento que lhes conferem particularidades. A noção de campo traduz a concepção social do autor (SETTON, 2002). Para Bourdieu (2004c), os campos são microcosmos sociais que possuem valores - capitais - objetos e interesses específicos, noção esta que demonstra a visão do autor acerca de uma sociedade heterogênea. Tais capitais, que são ao mesmo tempo instrumentos de poder e objetos de desejo, são apropriados e acumulados de forma desigual pelos agentes do campo, o que implica, para o presente estudo, que os agentes se apropriariam desigualmente do produto de um trabalho científico.

O campo social é uma configuração da distribuição desigual de diferentes tipos de capital (MISOCZKY, 2003), no qual os agentes e instituições se enfrentam de acordo com suas posições relativas dentro de seu espaço, conservando ou transformando a estrutura desse campo (BOURDIEU, 1996; BOURDIEU, 2004c). E, dentre os diferentes campos estudados pelo autor, está o campo científico, base sob a qual se configura a análise do presente artigo. 
O universo da ciência, para Bourdieu (2003), se submete às mesmas leis gerais da teoria dos campos (para ele, o "universo puro" da mais "pura" ciência é um campo social como outro qualquer, sendo, pois, permeado por relações de forças, lutas, estratégias e interesses). "Qualquer que seja o campo, ele é objeto de luta tanto em sua representação quanto em sua realidade" (BOURDIEU, 2004b, p. 29), assumindo ao mesmo tempo formas específicas no interior desse campo (as relações de lutas e forças se revestem de formas específicas em cada campo, o que se relaciona à sua característica de ser autônomo). De acordo com Bourdieu, o campo científico é

[...] o lugar e o espaço de uma luta concorrencial. O que está em luta são os monopólios da "autoridade científica" (capacidade técnica e poder social) e da "competência científica" (capacidade de falar e agir legitimamente, isto é, de maneira autorizada e com autoridade) que são socialmente outorgadas a um agente determinado (BOURDIEU, 2003, p. 112, grifos do autor).

Nesse campo, a percepção social vai além de questões puramente técnicas por envolver julgamentos simbólicos, pois o próprio julgamento sobre a capacidade técnica de um pesquisador está "contaminado" pelo conhecimento da posição que este ocupa nas hierarquias instituídas, como as escolas e universidades pelas quais tenha passado ou esteja atuando (BOURDIEU, 2003). Bourdieu (2004a) considera também a universidade como sendo um lugar de luta para saber quem está fundamentado para dizer a verdade sobre o mundo social.

Assim, o funcionamento do campo científico pressupõe uma forma específica de interesse, sendo então as práticas científicas relacionadas a um mesmo campo práticas interessadas, já que são orientadas para a aquisição de autoridade científica, como prestígio e reconhecimento. Porém, é importante ressaltar que não se utiliza aqui uma visão do campo científico como um campo unicamente orientado por forças e lutas, apenas enfatiza-se a dimensão política existente no mesmo, não considerando, como alerta Bourdieu, apenas determinações puras e puramente intelectuais dos conflitos científicos (BOURDIEU, 2003).

Essa dimensão política leva a uma lógica de distinção no campo científico, no qual acumular capital é fazer um "nome" conhecido e reconhecido. Nesse campo, o reconhecimento dos pares é importante para o pesquisador, pares estes que podem também ser concorrentes. Nesse sentido, a motivação do pesquisador não se relaciona apenas a uma satisfação intrínseca, porque seu trabalho precisa também ser importante para os outros. Nessa dinâmica, "o que é percebido como importante e interessante é o que tem chances de ser reconhecido da mesma forma por outros, aquilo com possibilidades de fazer 
aparecer aquele que o produz como importante e interessante aos olhos dos seus pares" (BOURDIEU, 2003, p. 115).

No campo científico, as estratégias empreendidas pelos indivíduos dependem da posição que ocupam no campo, posição esta influenciada pelos capitais que acumulam e pelo poder que este capital lhes confere. Para Bourdieu (2003), as estratégias daqueles que são dominantes no campo serão diferentes das estratégias dos novatos. Para o autor, elas serão logicamente opostas, sendo que os dominantes recorrem a estratégias de conservação para manter a ordem científica com que compactuam; e os novatos, ao se inserirem no campo de pesquisa, tomam a posição de aspirantes (em relação aos dominantes), assumindo uma lógica oposta de ação, podendo empreender estratégias de sucessão ou de subversão. As primeiras são estratégias mais seguras, por meio da adoção do ideal de excelência científica já estabelecido pela ordem. Já as últimas são estratégias mais arriscadas e de altos investimentos, que vão contra a lógica do sistema.

Cada campo possui seus capitais simbólicos enquanto objetos e interesses específicos. Relativamente ao campo científico, Bourdieu (2004b, p. 26) considera seu capital como "uma espécie particular de capital simbólico que consiste no reconhecimento (ou no crédito) atribuído pelo conjunto de paresconcorrentes no interior do campo" (BOURDIEU, 2004b, p. 26). O capital científico pode assumir diversas formas e proporcionar poder a seus detentores. Como exemplos práticos, índices de citações de trabalhos, prêmios, medalhas e traduções de produções para línguas estrangeiras. O autor especifica que há duas espécies de capital científico que, nesse caso, confeririam duas espécies também distintas de poder no campo, como se pode observar na Figura 1.

Figura 1 - As duas espécies de capital científico

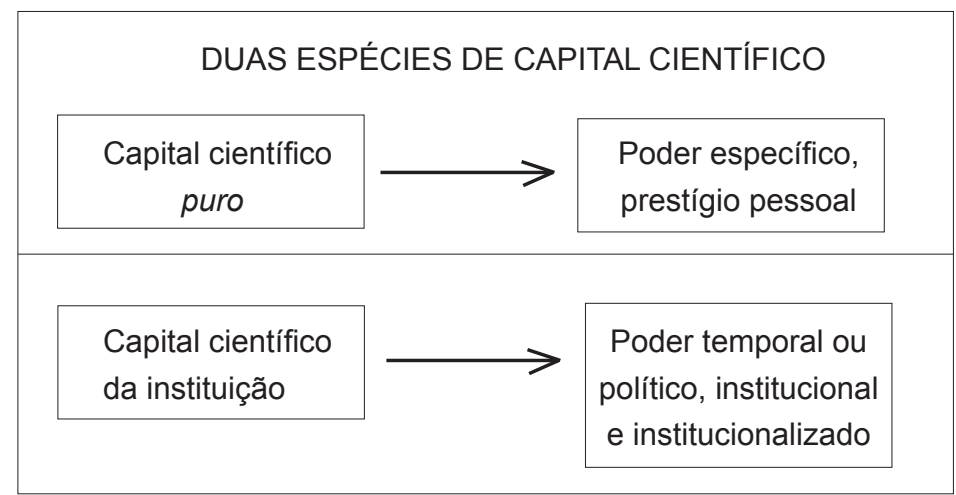

Fonte: Adaptado de Teixeira (2011, p. 60). 
Assim, há um poder específico ou prestígio pessoal, que se relaciona a um reconhecimento (pouco institucionalizado) pelos pares do campo; e um poder temporal ou político, institucional e institucionalizado relacionado à ocupação de posições que conferem poder nas instituições científicas, departamentos e comissões. Este poder político permite aos indivíduos acesso aos meios de produção e de reprodução dentro do campo, tais como contratos, créditos e o poder de nomear e de fazer carreira (BOURDIEU, 2004b, p. 35-36).

O poder específico adviria da acumulação de capital científico "puro", que está relacionado a contribuições do indivíduo ao progresso da ciência, invenções, descobertas e publicações, "especialmente nos órgãos mais seletivos e mais prestigiosos, portanto aptos a conferir prestígio à moda de bancos de crédito simbólico" (BOURDIEU, 2004b, p. 36). É um capital que está mais exposto a críticas, podendo ser combatido pelas instituições (BOURDIEU, 2004b).

Já o poder temporal ou político adviria da acumulação de capital científico institucional (da instituição), que se refere à aquisição

[...] por estratégias políticas (específicas) que têm em comum o fato de todas exigirem "tempo" - participação em comissões, bancas (de teses, concursos), colóquios mais ou menos convencionais no plano científico, cerimônias, reuniões etc." (BOURDIEU, 2004b, p. 36, grifos do autor).

Ele se insere em um contexto de regras burocráticas. Como o próprio nome sugere, é um capital institucionalizado (BOURDIEU, 2004b).

Relativamente à dinâmica de acumulação dos dois tipos de capitais descritos entre os indivíduos de um campo, dinâmica esta central para o presente estudo, Bourdieu (2004b) considera que,

Por razões práticas, o acúmulo das duas espécies de capital é [...] extremamente difícil. E, podem-se caracterizar os pesquisadores pela posição que eles ocupam nessa estrutura, isto é, pela estrutura: de seu capital científico ou, mais precisamente, pelo: peso relativo de seu capital "puro" e de seu capital "institucional": tendo, num extremo, os detentores de um forte crédito específico e de um frágil peso político e; no extremo oposto, os detentores de um forte peso político e de um frágil crédito científico (em especial, os administradores científicos) (BOURDIEU, 2004b, p. 38, grifos do autor).

Por crédito ou poder específico, entende-se aquele obtido pela acumulação de capital científico puro e, por peso ou poder político, aquele que é 
obtido pela acumulação de capital institucional. Teixeira (2011), buscando uma representação dessa dinâmica descrita por Bourdieu (2004b), apresenta a seguinte figura:

Figura 2 - Ocupação de posições no campo científico

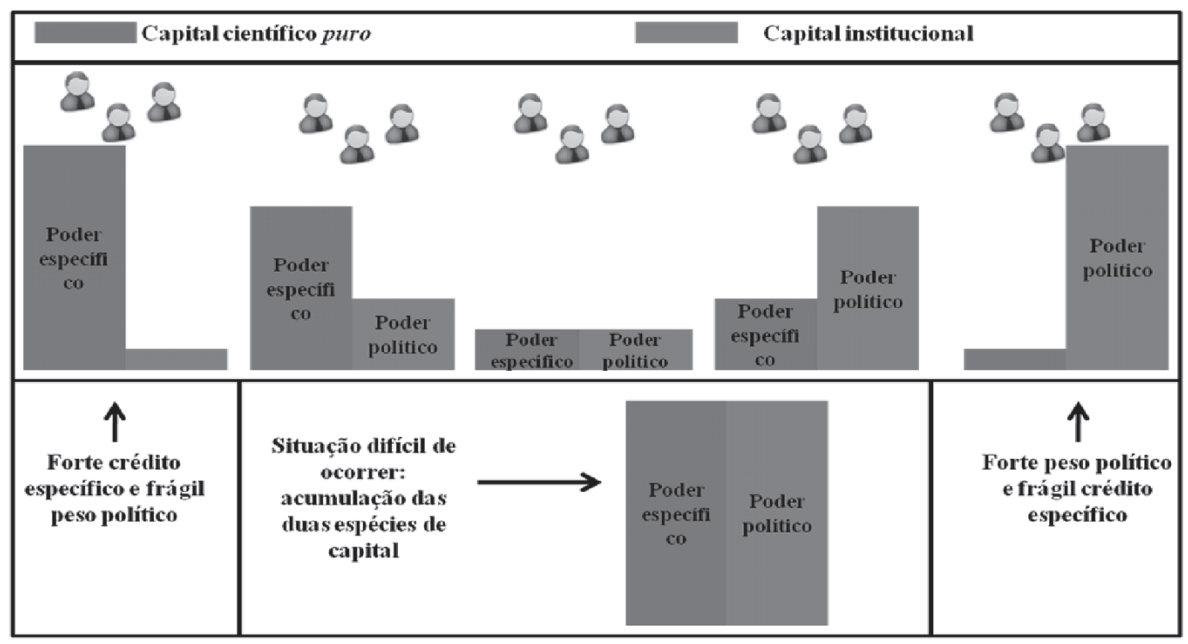

Fonte: Teixeira (2011, p. 63).

Bourdieu (2004b) considera que não há uma relação igualitária entre a possibilidade de se obter poder específico por meio de poder político, e a situação inversa, obter poder político por meio de poder específico. Acredita que a primeira possibilidade, ou seja, a conversão de capital político em científico, ocorra de maneira mais rápida, já que quem ocupa posições institucionais tem mais condições de assegurar a ortodoxia e a ordem científica estabelecida, exercendo poder sobre a produção e reprodução, como participações em conselhos universitários e bancas de concursos. Em contrapartida, a conversão de capital específico em político ocorre de forma mais tardia, já que acumular um forte poder específico favoreceria, de modo contínuo, a obtenção de poder político. Porém, não de uma forma tão rápida quanto a outra conversão. Assim, como outro objetivo específico do estudo, será observado se essa relação não igualitária entre as duas possibilidades ocorre na dinâmica de distribuição de fontes de capitais entre os docentes do programa analisado.

\section{PROCEDIMENTOS METODOLÓGICOS}

A presente pesquisa possui uma abordagem quantitativa e foi realizado um tratamento descritivo dos dados coletados, bem como qualitativa, devido ao 
caráter simbólico e interpretativo das análises empreendidas. Já que utilizamos os capitais científicos descritos por Bourdieu (2004b), bem como sua análise sobre o campo científico, ressaltamos que o autor utilizou em suas pesquisas tanto métodos qualitativos quanto quantitativos, já que criticava o monoteísmo metodológico e sugeria uma combinação de ambos os métodos (no seu caso, de análise estatística com entrevistas em profundidade), considerando que "a pesquisa é uma coisa demasiado séria e demasiado difícil para se poder tomar a liberdade de confundir a "rigidez", que é o contrário da inteligência e da invenção, com o "rigor"” (BOURDIEU, 1989, p. 26, grifos do autor). Dessa forma, justifica-se a utilização de método quantitativo para descrever a dinâmica de distribuição de capitais entre os docentes. Pois, já que se trata de um poder e de capitais de caráter simbólico, poder-se-ia pensar que o método quantitativo não seria o mais viável. Contudo, além do que já acabamos de descrever sobre o posicionamento de Bourdieu (1989) sobre a questão metodológica, algumas atividades utilizadas neste estudo como fontes de capitais científicos são as próprias atividades descritas pelo autor.

Trata-se de uma pesquisa exploratória, já que visa conhecer um fenômeno levantando suas características, desenvolvendo proposições que podem levar a pesquisas complementares (GIL, 1999; RICHARDSON, 1999; VARGAS, 2001). Como técnica de coleta de dados, foi utilizada a pesquisa documental, que consiste no exame de documentos que possuem valor científico em potencial (GODOY, 1995), sendo, neste caso, os currículos disponibilizados na Plataforma Lattes.

Foi utilizado ainda um corte transversal no tempo, sendo coletados os dados dos currículos referentes a um período de 5 anos (janeiro de 2005 a janeiro de 2010). Esse período foi escolhido por permitir ao mesmo tempo uma análise da distribuição de fontes de capitais que ocorria no momento de coleta de dados, bem como que se apreendesse a dinâmica de distribuição de fontes de capitais por certo período de tempo, já que a posição ocupada pelos docentes depende da acumulação de capitais. Não foi considerado um tempo maior do que cinco anos, dado que as regras do campo que levam a obtenção de tais fontes podem se alterar ao longo do tempo, bem como o valor das fontes desses capitais, o que poderia levar a uma análise de dados muito heterogêneos.

O contexto de análise foi o de um programa de pós-graduação Stricto-Sensu da área de Ciências Sociais Aplicadas que se situa em uma cidade do interior de Minas Gerais (Brasil). Este programa possui 36 anos e oferta curso de Mestrado e de Doutorado. No momento de coleta de dados, ele contava com 23 docentes atuando como professores de disciplinas da pós-graduação e/ou orientadores de Mestrado e/ou Doutorado, bem como em disciplinas da graduação. 
Indica-se a possibilidade de erros não amostrais na pesquisa, devido à dependência dos dados disponibilizados pelos docentes em seus currículos Lattes, uma vez que essa disponibilização é feita de forma diferenciada, inclusive com a existência de alguns dados incompletos, o que forçou algumas adaptações no tratamento dos dados, até mesmo nos critérios de pontuação. Contudo, tentou-se realizar tais adaptações de forma proporcional, buscando minimizar possíveis distorções.

Com base nos dados dos currículos, os docentes tiveram suas atividades descritas e pontuadas com base nas próprias regras de pontuação utilizadas pelo programa de pós-graduação para avaliação de currículos de candidatos em processos de seleção para Mestrado e Doutorado ${ }^{1}$. A referida quadro foi obtida por meio do próprio endereço eletrônico do programa.

Como dados para descrever as fontes de capital científico puro (poder ou crédito específico), foram consideradas a formação acadêmica do docente (atribuindo pontos específicos para títulos de especialização, mestrado, doutorado, pós-doutorado, sendo também considerado o conceito CAPES $^{2}$ do curso em que formaram), bem como atividades ligadas ao ensino, pesquisa e extensão. Tais atividades, diretamente relacionadas com o que Bourdieu (2004b) considera como inerente ao capital científico puro, compreendiam: (1) ensino, como aulas ministradas e orientações acadêmicas; (2) pesquisa, como coordenação e participação em projetos de pesquisa, consultoria ad hoc de revistas, participação em congressos, publicações em periódicos e eventos (considerando o conceito Qualis dos mesmos ${ }^{3}$ ), livros, capítulos de livros e boletim técnicos; (3) extensão, como registros ou solicitações de patentes, coordenação e participação em projetos de extensão, cursos de extensão ministrados e participações em eventos de extensão; e, por fim, (4) prêmios de destaques recebidos pelos docentes. Essas atividades consideradas estão descritas no Quadro 1.

1 Sugere-se, para futuras pesquisas, que as regras de pontuação utilizadas pela Capes para avaliação dos programas de pós-graduação sejam utilizadas, ao invés de regras internas do programa. Neste estudo, optou-se pela pontuação do próprio programa para observar o que se considera importante especificamente em seu ambiente. Trata-se, então, de uma visão mais interna, ainda que esta esteja relacionada às regras da Capes.

2 O conceito Capes refere-se a conceitos obtidos por programas de pós-graduação brasileiros em avaliações trienais que a Capes realiza, atribuindo conceitos entre 1 e 7 a esses programas, sendo que "o programa com nível de avaliação igual ou superior a 3 tem seus diplomas validados e reconhecidos nacionalmente. O programa que oferece apenas o mestrado tem seu nível limitado a 5, ficando os níveis 6 e 7 reservados para os doutorados de referencial internacional" (MIRANDA; ALMEIDA, 2004, p. 52).

3 "Qualis é o conjunto de procedimentos utilizados pela Capes para estratificação da qualidade da produção intelectual dos programas de pós-graduação. [...] A estratificação da qualidade dessa produção é realizada de forma indireta. Dessa forma, o Qualis afere a qualidade dos artigos e de outros tipos de produção, a partir da análise da qualidade dos veículos de divulgação, ou seja, periódicos científicos. A classificação de periódicos é realizada pelas áreas de avaliação e passa por processo anual de atualização. Esses veículos são enquadrados em estratos indicativos da qualidade - A1, o mais elevado; A2; B1; B2; B3; B4; B5; C - com peso zero." (CAPES, 2011). 


\section{Quadro 1 - Atividades consideradas como fontes de capital científico puro ou crédito específico}

\begin{tabular}{|c|c|}
\hline \multicolumn{2}{|c|}{ Atividades consideradas como fontes de capital científico puro } \\
\hline Formação Acadêmica & Pesquisa (continuação) \\
\hline Especialização & Publicação em periódico Qualis B1 \\
\hline Mestrado (considerando Conceito Capes) & Publicação em periódico Qualis B2 \\
\hline Doutorado (considerando Conceito Capes) & Publicação em periódico Qualis B3 \\
\hline Pós-Doutorado (considerando Conceito Capes) & Publicação em periódico Qualis B4 \\
\hline Ensino & $\begin{array}{l}\text { Publicação em periódico Qualis C ou sem } \\
\text { classificação }\end{array}$ \\
\hline Aulas ministradas graduação & $\begin{array}{l}\text { Artigo ou resumo estendido em eventos } \\
\text { Qualis A }\end{array}$ \\
\hline Aulas ministradas pós Stricto Sensu & $\begin{array}{l}\text { Artigo ou resumo estendido em eventos } \\
\text { Qualis B }\end{array}$ \\
\hline Aulas ministradas pós Lato Sensu & $\begin{array}{l}\text { Artigo ou resumo estendido em eventos } \\
\text { Qualis C ou sem classificação }\end{array}$ \\
\hline $\begin{array}{l}\text { Orientação acadêmica graduação (monografia e } \\
\text { iniciação científica) }\end{array}$ & Resumos em eventos \\
\hline Orientação acadêmica Lato Sensu (monografia) & Livro \\
\hline Orientação acadêmica Stricto Sensu (mestrado) & Capítulo em livro \\
\hline Orientação acadêmica Stricto Sensu (doutorado) & Boletim técnico \\
\hline Pesquisa & Extensão \\
\hline $\begin{array}{l}\text { Coordenação de projeto de pesquisa com finan- } \\
\text { ciamento }\end{array}$ & $\begin{array}{l}\text { Registro ou solicitação de registro de } \\
\text { patente }\end{array}$ \\
\hline $\begin{array}{l}\text { Coordenação de projeto de pesquisa sem finan- } \\
\text { ciamento }\end{array}$ & $\begin{array}{l}\text { Coordenação de projeto de extensão } \\
\text { apoiado por agência de fomento }\end{array}$ \\
\hline Membro de projeto de pesquisa com financiamento & $\begin{array}{l}\text { Coordenação de projeto de extensão sem } \\
\text { apoio de agência de fomento }\end{array}$ \\
\hline Membro de projeto de pesquisa sem financiamento & $\begin{array}{l}\text { Membro de projeto de extensão apoiado } \\
\text { por agência de fomento }\end{array}$ \\
\hline Consultor ad hoc de revista classificada Qualis & $\begin{array}{l}\text { Membro de projeto de extensão sem apoio } \\
\text { de agência de fomento }\end{array}$ \\
\hline $\begin{array}{l}\text { Consultor ad hoc de revista sem classificação } \\
\text { Qualis }\end{array}$ & Curso de extensão ministrado \\
\hline $\begin{array}{l}\text { Participação de congressos Qualis com apresen- } \\
\text { tação }\end{array}$ & Participação em curso de extensão \\
\hline Participação de congressos Qualis como ouvinte & Membro em evento de extensão \\
\hline Publicação em periódico Qualis A1 & Prêmios \\
\hline Publicação em periódico Qualis A2 & Prêmios de destaques \\
\hline
\end{tabular}


Já quanto às fontes de capital institucional (ou crédito ou poder político), foi considerada a ocupação de cargos em conselhos, comissões, consultorias, cargos administrativos em departamentos, cursos, cujo direito de ocupação advém de nomeações e documentos legalmente considerados no âmbito interno da universidade; bem como participações em bancas de trabalhos de conclusão de curso de graduação, monografias de cursos de especialização, dissertações e teses. Dada a diversidade possível de cargos a serem ocupados, bem como a não existência de critérios de pontuação por parte do programa para os mesmos, optou-se por considerar os níveis hierárquicos já existentes na universidade do programa analisado, baseando-se no organograma disponibilizado no próprio site da instituição. Em seguida, atribuíram-se pontos específicos para cada um dos níveis nos quais os cargos poderiam estar situados. No Quadro 2, são especificadas as pontuações atribuídas para cada nível e, especificamente, para as participações em bancas $^{4}$, fontes de crédito específico explicitamente tratadas por Bourdieu (2004b), por conferir ao participante tanto poder de decisão quanto de assegurar a ordem científica prevalecente:

\section{Quadro 2 - Pontuações atribuídas às fontes de capital institucional ou crédito político}

\begin{tabular}{|c|c|c|c|}
\hline Nivel hierár qui co do car go ocupado pelo docente & Valor & Participações em bancas: & Valor \\
\hline Nível 1 - Conselhos e Ouvidoria & 70 & Presidente de banca para concurso de docente & 20 \\
\hline Nivel 2 - Reitoria & 50 & Membro de banca para concurso de docente & 15 \\
\hline Nível 2A - Gabinete da Reitoria e Comissões da Reitoria & 45 & Membro de banca de tese & 10 \\
\hline Nível 3 - Pró-Reitorias & 40 & Membro de banca de dissertação & 8 \\
\hline Nível 4 - Órgãos diretamente subordinados às Pró-Reitorias & 30 & Membro de banca de monografia de curso lato-sensu & 6 \\
\hline Nível5 - Órgãos diretamente subordinados às Superintendências & \multirow{2}{*}{20} & Membro de banca de trabalho de conclusão de curso & \multirow{3}{*}{4} \\
\hline da Pró-Reitoria de Planejamento e Gestão & & de graduação & \\
\hline Nível 6-Departamentos dos cursos & 10 & & \\
\hline
\end{tabular}

Dessa forma, os currículos foram pontuados de forma a separar as fontes de crédito específico e crédito político para que se observasse a dinâmica de distribuição de fontes de capitais e se respondesse aos objetivos da pesquisa.

\section{DINÂMICA DE DISTRIBUIÇÃO DE FONTES DE CAPITAIS CIENTÍFICOS ENTRE OS DOCENTES DO PROGRAMA ANALISADO}

Os docentes tiveram seus currículos pontuados, em primeiro lugar, com relação às atividades relacionadas ao capital científico puro. Em seguida, foram

4 Foi necessário estabelecer uma pontuação para a participação em bancas, já que não há este tipo de atividade representada no organograma da universidade, por não se tratar de um cargo específico e, sim, de uma atuação temporária para determinados fins. 
elencados em ordem decrescente de pontuação, para que pudesse ser analisada não só como se dá a distribuição dos capitais, como, principalmente, aqueles que obtiveram maiores e menores pontuações. Neste caso, considera-se que os pontos obtidos demonstrem níveis de acumulação de capitais científicos puros por parte dos docentes, o que lhes confere um maior ou menor poder específico dentro do programa. Nesse sentido, os resultados demonstram o panorama representado no Quadro 3.

\section{Quadro 3 - Posições ocupadas pelos docentes em relação}

\begin{tabular}{|c|c|c|c|}
\hline \multicolumn{2}{|c|}{ Grupos } & Docentes & Total de Pontos \\
\hline \multirow{6}{*}{ Grupo A (6 docentes) } & \multirow{3}{*}{ A1 ( 3 docentes) } & Docente A & 1050,25 \\
\hline & & Docente B & 987,5 \\
\hline & & Docente C & 952 \\
\hline & \multirow{3}{*}{ A2 (3 docentes) } & Docente D & 939 \\
\hline & & Docente E & 917,5 \\
\hline & & Doce nte F & 829 \\
\hline \multirow{10}{*}{ Grupo B ( 10 docentes) } & \multirow{3}{*}{ B1 (3 docentes) } & Docente G & 748,5 \\
\hline & & Docente H & 742,5 \\
\hline & & Docente I & 680,5 \\
\hline & \multirow{7}{*}{ B2 (7 docentes) } & Docente J & 606,5 \\
\hline & & Docente $\mathrm{K}$ & 605 \\
\hline & & Doce nte L & 585 \\
\hline & & Doce nte M & 546,5 \\
\hline & & Doce nte $\mathbf{N}$ & 537 \\
\hline & & Docente $O$ & 523,5 \\
\hline & & Doce nte $P$ & 510,5 \\
\hline \multirow{7}{*}{ Grupo $\mathrm{C}(7$ docentes) } & \multirow{3}{*}{ C1 (3 docentes) } & Docente $\mathrm{Q}$ & 470,5 \\
\hline & & Doce nte $R$ & 448,5 \\
\hline & & Docente S & 364 \\
\hline & \multirow{4}{*}{$\mathrm{C} 2$ (4 docentes) } & Doce nte $T$ & 331 \\
\hline & & Docente U & 323,75 \\
\hline & & Docente V & 249,5 \\
\hline & & Doce nte $X$ & 226,5 \\
\hline
\end{tabular}

Para a divisão dos docentes, optou-se pela adoção de três grupos (para que se conhecessem aqueles situados nos extremos, e aqueles considerados medianos) obtidos por intervalos iguais de pontuação. Para tanto, subtraiu-se a maior pontuação obtida pela menor $(1050,25$ - 226,5) para que se conhecesse a amplitude das pontuações, que foi de 823,75 . Tal amplitude foi divida então em três, para que se definisse, por sua vez, a amplitude dos intervalos, que foi de 274,58. Construídos então os três intervalos, os docentes foram classificados dentro de cada um dos mesmos: 


\section{Quadro 4 - Demonstração do procedimento adotado para a divisão dos docentes em grupos}

\begin{tabular}{|c|c|}
\hline Grupo & Intervalo de Pontos \\
\hline A & $775,67-1050,25$ \\
\hline B & $501,09-775,66$ \\
\hline C & $226,5-501,08$ \\
\hline
\end{tabular}

O mesmo procedimento foi adotado para a divisão em subgrupos, porém, com a intenção de se utilizar dois e não três subgrupos. Os resultados demonstram uma grande amplitude em relação à acumulação de créditos específicos, o que demonstra haver níveis significativamente diferentes de acumulação de capitais científicos puros por parte do corpo docente. Ainda, os resultados demonstram que há uma parcela menor de docentes acumulando uma maior parte de capital ( $26 \%$ acumulam $40 \%$ do total de pontos do corpo docente), como se pode observar no Quadro 5.

\section{Quadro 5 - Percentuais de acumulação de pontos referentes a crédito específico}

\begin{tabular}{|c|c|c|c|}
\hline Grupo & Percentual de docentes no grupo & Pontos acumulados & Percentual de acumulação \\
\hline A & $26 \%$ & 5675,25 & $40 \%$ \\
\hline B & $43 \%$ & 6085,5 & $43 \%$ \\
\hline C & $30 \%$ & 2413,75 & $17 \%$ \\
\hline Total & $\mathbf{1 0 0} \%$ & $\mathbf{1 4 1 7 4 , 5}$ & $\mathbf{1 0 0} \%$ \\
\hline
\end{tabular}

Ou seja, não há uma distribuição uniforme entre as fontes de capital científico puro, o que demonstra uma dinâmica em que uma parcela menor de docentes do programa seja possivelmente reconhecida como maior acumuladora de crédito específico. Há, assim, a ocupação pelos docentes de diferentes posições dentro do campo específico do programa analisado, o que pode lhes dar diferentes possibilidades de agência ${ }^{5}$, se for considerada a consideração de Bourdieu (2004b) a respeito.

Se a dinâmica do campo científico é baseada em conhecimento e reconhecimento, a ocupação de diferentes posições no mesmo implica não só em diferentes níveis de reconhecimento pelos próprios pares do campo, como também diferentes níveis de reconhecimento externo (prestígio do ponto de vista interno

5 Entende-se possibilidade de agência como a "capacidade do sujeito de reinterpretar e mobilizar um conjunto de recursos (padrões sociais) de forma própria” (ARAÚJO, 2008, p. 51). 
e externo). Além disso, as diferenciações existentes podem influenciar as lutas e disputas no campo, pois uma maior acumulação de fontes de capital científico pode implicar em sua utilização como instrumentos de poder.

A coleta de tais dados permite também analisar de que forma os docentes têm respondido à complexidade inerente a seu papel na universidade, como foi descrito no referencial. Já que a universidade precisa desenvolver atividades ligadas a ensino, pesquisa e extensão, tal lógica também se estende ao trabalho dos docentes. Nesse sentido, observou-se a distribuição de fontes de capitais relativamente à área de atuação acadêmica apresentada na Quadro 6.

\section{Quadro 6 - Origem dos pontos recebidos pelo corpo docente em relação a crédito específico}

\begin{tabular}{|c|c|c|}
\hline Origem & Pontos totais do corpo docente & Percentual \\
\hline Pesquisa (Jan.2005-Jan.2010) & 7728,5 & $54,5 \%$ \\
\hline Ensino (Jan.2005-Jan.2010) & 5761 & $40,6 \%$ \\
\hline Formação Acadêmica & 511 & $3,6 \%$ \\
\hline Extensão (Jan.2005-Jan.2010) & 129 & $0,9 \%$ \\
\hline Prêmios (Jan.2005-Jan.2010) & 45 & $0,3 \%$ \\
\hline Total de Pontos & 14174,5 & $100,0 \%$ \\
\hline
\end{tabular}

Dessa forma, principalmente pelos próprios critérios de pontuação utilizados pelo programa (que atribuem maiores pesos para atividades relacionadas à pesquisa), observa-se uma valorização à pesquisa, seguida pelo ensino. A extensão, por sua vez, não ocupa um papel muito relevante, tanto no que se refere ao baixo valor atribuído às atividades desta natureza, quanto à dedicação dos docentes à área. A significativa valorização da pesquisa em contraposição à pouca valorização da extensão pode indicar a percepção, dentro do campo, daquilo que é "importante" e pode conferir reconhecimento ao pesquisador.

Partindo para a análise da distribuição de fontes de capital institucional, que podem conferir aos docentes um poder de caráter político, referente a capacidades de tomadas de decisões e de influência na ordem científica vigente, foram identificados os cargos ocupados pelos docentes na universidade, considerando os níveis hierárquicos descritos nos procedimentos metodológicos.

Considerando as pontuações também descritas nos procedimentos metodológicos, os resultados indicaram a distribuição presente no Quadro 7. 
Quadro 7 - Posições ocupadas pelos docentes em relação a fontes de capital institucional ou crédito político

\begin{tabular}{|c|c|c|c|}
\hline Docente & Pontos & $\begin{array}{c}\text { Sub-grupos } \\
\text { Crédito Político }\end{array}$ & $\begin{array}{l}\text { Grupos } \\
\text { Crédito Político }\end{array}$ \\
\hline Docente A & 952 & A1 (1 docente) & Grupo A (2 \\
\hline Docente F & 940 & A2 (1 docente) & docentes) \\
\hline Docente J & 649 & \multirow{4}{*}{ B1 (4 docentes) } & \multirow{8}{*}{$\begin{array}{l}\text { Grupo B (8 } \\
\text { docentes) }\end{array}$} \\
\hline Docente I & 592 & & \\
\hline Docente B & 556 & & \\
\hline Docente G & 539 & & \\
\hline Docente R & 485 & \multirow{4}{*}{ B2 (4 docentes) } & \\
\hline Docente $\mathbf{N}$ & 416 & & \\
\hline Docente $\mathbf{Q}$ & 397 & & \\
\hline Docente C & 376 & & \\
\hline Docente $\mathrm{E}$ & 354 & \multirow{6}{*}{ C1 (6 docentes) } & \multirow{13}{*}{$\begin{array}{l}\text { Grupo C (13 } \\
\text { docentes) }\end{array}$} \\
\hline Docente $\mathbf{P}$ & 349 & & \\
\hline Docente V & 291 & & \\
\hline Docente M & 249 & & \\
\hline Docente 0 & 226 & & \\
\hline Docente $\mathbf{H}$ & 219 & & \\
\hline Docente D & 216 & \multirow{7}{*}{ C 2 (7 docentes) } & \\
\hline Docente T & 211 & & \\
\hline Docente L & 178 & & \\
\hline Docente K & 177 & & \\
\hline Docente U & 160 & & \\
\hline Docente s & 104 & & \\
\hline Docente $\mathrm{X}$ & 80 & & \\
\hline
\end{tabular}

Os intervalos também foram divididos seguindo os mesmos procedimentos utilizados quanto ao crédito específico, formando também três grupos de docentes. Neste caso, observa-se que apenas dois docentes situaram-se no primeiro grupo referente à ocupação de cargos políticos. Além disso, há uma maior incidência de docentes ocupando posições fracas (grupo C) no que se refere ao poder político, somando $65,2 \%$ do total. Assim, repetindo a mesma lógica ocorrida com o crédito específico, há uma concentração de maiores fontes de poder político por parte de uma minoria. Porém, de forma ainda mais evidente do que a observada para o crédito específico. A própria análise da Quadro 3 demonstra haver seis docentes ocupando o grupo A de poder específico, enquanto, analisando a Quadro 7, há apenas dois docentes ocupando o grupo A de poder político.

Nesse sentido, a ocupação de posições de destaque no nível de execução de atividades fontes de capital científico puro não necessariamente é acompanhada 
de uma maior influência política no que se refere à acumulação de cargos políticos ou decisórios. Isso pode ocorrer tanto por uma falta de desejo dos próprios docentes pela ocupação de cargos políticos, como também pelo próprio fato de que as "vagas" nessas posições de tomadas de decisão são menores do que o número de docentes que atuam nas mais diversas atividades acadêmicas que envolvem ensino, pesquisa e extensão. Se considerarmos a dimensão política de análise, que é sobre a qual nos debruçamos, uma proposição é a de que a conversão de crédito específico em crédito político seja mais difícil de ocorrer do que a conversão inversa (crédito político em crédito específico), como considera Bourdieu (2004b).

Essa proposição pode ser mais bem explorada se fizermos uma análise comparativa entre a acumulação de capital científico puro (crédito específico) e a acumulação de capital institucional (crédito político), análise esta que permitirá também que se atinjam os objetivos principal e específicos do estudo. O Quadro 8 demonstra os resultados de forma conjugada, sendo os docentes identificados com as mesmas cores atribuídas a cada subgrupo no qual se situaram em relação ao crédito específico (no Quadro 3).

\section{Quadro 8 - Conjugação das posições ocupadas pelos docentes em relação a fontes de crédito específico e político}

\begin{tabular}{|c|c|c|c|c|}
\hline Docente & Pontos & $\begin{array}{l}\text { Sub-grupos em que se encontram } \\
\text { quanto ao crédito es pecifico }\end{array}$ & $\begin{array}{c}\text { Sub-grupos } \\
\text { Crédito Político }\end{array}$ & $\begin{array}{c}\text { Grupos } \\
\text { Crédito Político }\end{array}$ \\
\hline Docente A & 952 & A1 & A1 & G \\
\hline Docente F & 940 & A2 & A2 & Grupo \\
\hline Docente J & 649 & $\mathrm{~B} 2$ & \multirow{4}{*}{ B1 } & \multirow{8}{*}{ Grupo B } \\
\hline Docente I & 592 & B1 & & \\
\hline Docente B & 556 & A1 & & \\
\hline Docente G & 539 & B1 & & \\
\hline Docente R & 485 & C1 & \multirow{4}{*}{$B 2$} & \\
\hline Docente N & 416 & $\mathrm{B2}$ & & \\
\hline Docente Q & 397 & $\mathrm{C} 1$ & & \\
\hline Docente C & 376 & A1 & & \\
\hline Docente $\mathbf{E}$ & 354 & A2 & \multirow{6}{*}{ C1 } & \multirow{13}{*}{ Grupo C } \\
\hline Docente $\mathrm{P}$ & 349 & $B 2$ & & \\
\hline Docente V & 291 & $\mathrm{C} 2$ & & \\
\hline Docente M & 249 & $B 2$ & & \\
\hline Docente O & 226 & B2 & & \\
\hline Docente $\mathrm{H}$ & 219 & B1 & & \\
\hline Docente D & 216 & $\mathrm{~A} 2$ & \multirow{7}{*}{$\mathrm{C} 2$} & \\
\hline Docente T & 211 & $\mathrm{C} 2$ & & \\
\hline Docente L & 178 & B2 & & \\
\hline Docente K & 177 & $B 2$ & & \\
\hline Docente U & 160 & C2 & & \\
\hline Docente S & 104 & C1 & & \\
\hline Docente X & 80 & $\mathrm{C} 2$ & & \\
\hline
\end{tabular}


Confrontando os resultados do crédito específico com os resultados do crédito político, observa-se que somente oito dos vinte e três docentes continuaram ocupando os mesmos subgrupos, ou seja, ocupam a mesma posição no que se refere a crédito específico e político. Nesses casos, demonstra-se uma possível conversão de um crédito no outro. O que se destaca nos resultados é que os dois docentes com maior crédito específico continuaram ocupando exatamente o mesmo subgrupo para os dois tipos de créditos, ou seja, acumulam de forma expressiva os dois tipos de capitais.

Para analisar se há uma polarização entre docentes com maior poder político (e fraco poder específico) de um lado, e docentes com maior poder específico (e fraco poder político) de outro (um dos objetivos específicos da pesquisa), optou-se por considerar a posição ocupada pelos docentes em relação aos grupos. Assim, os resultados demonstrados na Quadro 8 permitem a configuração do seguinte panorama:

Figura 3 - Distribuição de capitais científicos entre os docentes do programa Stricto-Sensu analisado

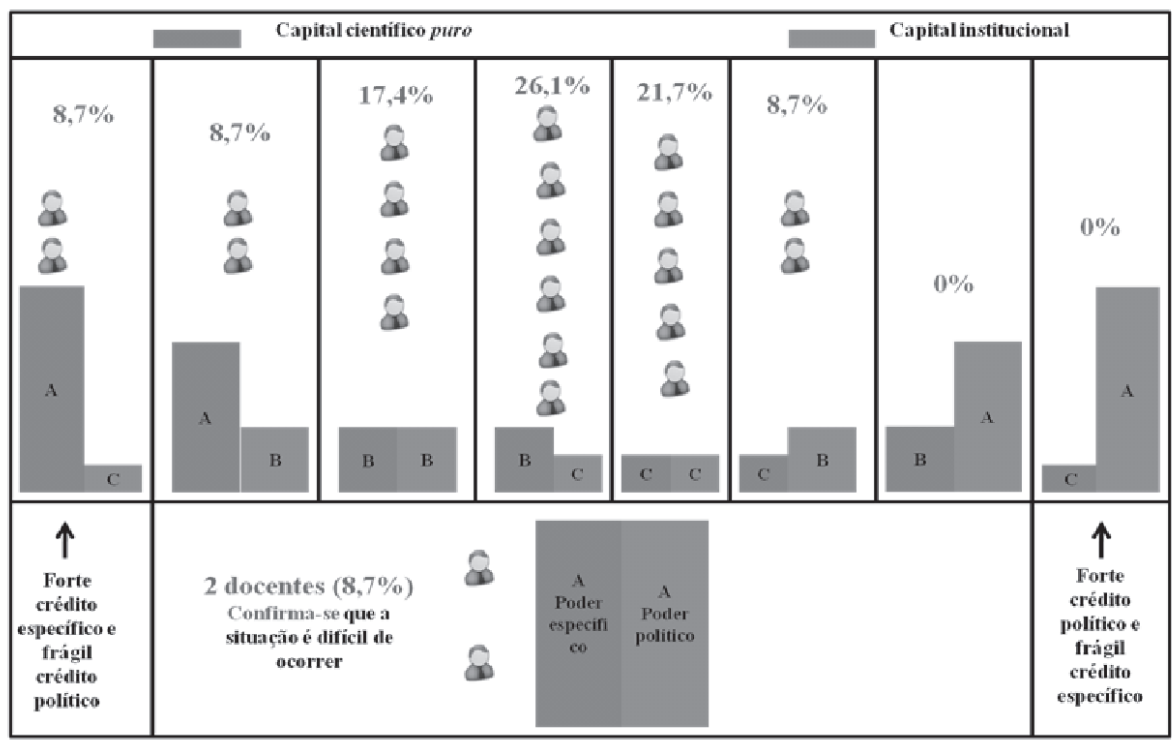

A distribuição de capitais científicos entre os docentes permite as seguintes análises:

- como se pode observar na parte inferior da Figura 3, apenas dois docentes, ou seja, $8,7 \%$, acumulam de forma expressiva ambos os tipos de capitais 
científicos, sendo, portanto, uma situação não muito comum de fato entre os docentes, assim como supõe Bourdieu (2004b);

- analisando as situações extremas e polares, em que se possuem níveis de acumulação inversamente proporcionais dos dois tipos de capitais, observa-se que não se trata também de uma situação muito comum entre os docentes, o que contraria as iniciais suposições baseadas na dinâmica descrita por Bourdieu (2004b). Pois apenas dois docentes (8,7\%) possuem um forte crédito específico e um frágil peso político. Em contrapartida, nenhum docente possui, simultaneamente, um forte crédito político e um frágil crédito específico. Tal análise permite demonstrar que a maioria dos docentes do programa se encontra em posições medianas, nas quais ocorre um maior equilíbrio entre a acumulação de fontes dos dois tipos de capitais, dividindo-se entre atividades que lhes conferem crédito específico e político;

- por outro lado, as observações contidas no tópico anterior podem indicar a diferença apontada pelo autor quanto às possibilidades de conversão de um capital em outro, já que o mesmo supõe que :

a conversão do capital político [...] em poder científico é [...] mais fácil e mais rápida, sobretudo para os que [...] estão aptos a exercer (poder) sobre a produção e a reprodução (participação no Conselho [...] das Universidades, nas comissões [...], nas bancas de concursos [...] (BOURDIEU, 2004b, p. 39).

Pois, enquanto há pelo menos dois docentes com forte poder científico, mas frágil poder político; não há nenhum docente com forte poder político e frágil poder específico. Ou seja, não houve casos em que um forte poder político não tenha sido acompanhado por um significativo poder específico. Tal análise confirma o pressuposto acima discutido de que a conversão de crédito específico em político possa ser mais difícil do que a conversão inversa - político em específico.

Uma ressalva importante a se fazer no estudo é que não se pretende defender que as atividades dos docentes utilizadas como referência de fontes de capital científico puro e capital científico institucional o sejam de forma categórica, já que estamos tratando de uma dinâmica que envolve um poder simbólico. Sendo assim, vários podem ser os capitais valorizados em cada campo específico de análise. Não pretendemos, dessa forma, afirmar que tais atividades, por si só, confiram poder aos docentes, principalmente porque se trata de um poder baseado em uma dinâmica de conhecimento e reconhecimento em que a posição ocupada não tem valor por si só, seu valor é relativo, depende da posição 
ocupada pelos outros docentes / pesquisadores do campo. Falamos, assim, de um poder simbólico que não pode ser possuído, ele é fruto das relações entre as posições sociais dos indivíduos no campo.

A pesquisa permitiu observar como os docentes respondem às várias demandas que lhes são apresentadas no exercício de sua profissão, profissão esta que perpassa por atividades relacionadas tanto à educação, quanto à pesquisa e às atividades que lhes são inerentes. Sendo assim, estão imersos em vários subcampos cujas leis de funcionamento $\left(\right.$ o nomos $\left.^{\sigma}\right)$ se submetem ao campo da ciência, no qual a legitimação por intermédio da palavra que é publicada, os títulos acadêmicos, e a pesquisa científica são realizações que se convertem em capitais valorizados no mesmo.

\section{CONSIDERAÇÕES FINAIS}

O presente estudo objetivou, embasando-se nos conceitos de campo e capital científicos de Bourdieu, analisar a dinâmica de distribuição de fontes de capitais científicos entre os docentes de um programa de pós-graduação Stricto-Sensu de uma universidade brasileira. Relativamente a este objetivo, observou-se que os docentes se dividem, em sua maioria, entre atividades que lhes conferem crédito específico e crédito político dentro do campo, ocupando posições medianas dentro da distribuição de capitais científicos puros e institucionais. Confirmou-se, ainda, na realidade do programa analisado, a consideração de Bourdieu (2004b) de que há a dificuldade de acumulação expressiva de ambos os tipos de capitais por parte de um pesquisador, já que apenas dois docentes ocupam posições de destaque em relação aos dois tipos de créditos.

Um objetivo específico do estudo era analisar se os docentes que ocupam mais cargos políticos possuem menos prestígio do ponto de vista de produção acadêmica e, a situação inversa, se quem possui mais prestígio acadêmico ocupa de forma menos expressiva cargos políticos, para o qual se tinha como pressuposto que haveria uma polarização entre os docentes que acumulam mais fontes de capital institucional, de um lado, e aqueles que acumulam fontes de capital científico puro, de outro. Este pressuposto não foi confirmado, dado que não houve uma expressiva ocupação de posições extremas

6 O nomos é um conceito de Bourdieu que se relaciona a propriedades gerais que ele considera para todos os campos. Ele "congrega as leis gerais, invariantes, de funcionamento do campo. [...] Todo campo, como produto histórico, tem um nomos distinto. Por exemplo, o campo artístico, instituído no século XIX, tinha como nomos: "a arte pela arte". Tanto a doxa como o nomos são aceitos, legitimados no meio e pelo meio social conformado pelo campo" (THIRY-CHERQUES, 2006, p. 37). 
inversamente proporcionais, ou seja, não houve uma polarização significativa entre os docentes com forte crédito político e frágil crédito específico de um lado, e forte crédito específico e frágil poder político, de outro. Nesse sentido, o pressuposto que se construiu com base nas considerações de Bourdieu (2004b) não foi confirmado.

Outro objetivo específico foi analisar se havia uma relação igualitária entre as possibilidades de conversão de capital específico em político, e vice-eversa. Observou-se que não, pois há uma maior facilidade de conversão de capital político em capital específico, se analisarmos a dinâmica apreendida de distribuição dos capitais (observação esta que corrobora com o que considera Bourdieu (2004b)).

Assim, em termos teóricos, algumas considerações do autor foram confirmadas e outras não, já que estamos tratando de um contexto específico de análise. Nesse sentido, o estudo contribui para estimular reflexões acerca das considerações do autor sobre o campo científico e estimular também novos estudos que permitam aprofundar a análise de outros contextos no campo da ciência, com suas diversas facetas e particularidades. O próprio autor questionava a leitura meramente teórica de seus conceitos, recomendando que suas teorias fossem colocadas em jogo (BRANDÃO, 2010). Nesse sentido, inclusive, Brandão (2010, p. 229, grifos do autor) considera que "a maioria das análises equivocadas sobre a obra de Bourdieu decorre [...] quer de leituras meramente teóricas, quer de leituras pretensamente "ortodoxas", pois o próprio autor assinalou a importância de trabalhar com e contra os autores [...]". Dessa forma, os resultados obtidos com o estudo caminham tanto com quanto contra as afirmações do autor sobre a dinâmica do campo científico no que diz respeito ao programa específico analisado.

É importante ressaltar que a opção teórica desta pesquisa implica na consideração de uma dimensão não só simbólica das atividades dos docentes, mas também a considerar que o campo científico está envolto por relações de poder. Uma decorrência do estudo foi a observação de que poucos docentes ocupam uma maior parcela de fontes de capitais científicos detidas por todo o quadro de docentes. Tal decorrência e as outras aqui apresentadas foram possíveis por meio do pensar relacional defendido por Bourdieu (1989). Assim como para o autor, o objeto de pesquisa não se encontra isolado de um conjunto de relações (BOURDIEU, 1989), os docentes não estão isolados no campo do programa de pós-graduação analisado, bem como sua acumulação de capital está envolvida em uma dinâmica que envolve os outros docentes. E é justamente este pensar relacional que permite que se pense o campo estudado 
como um campo de poder. A acumulação desigual de capitais configura um campo marcado por lutas e interesses.

Em relação à complexidade inerente ao papel do docente nas universidades, o estudo contribui no sentido de demonstrar uma valorização das atividades de pesquisa e ensino em detrimento às atividades de extensão, valorização esta duplamente observada, tanto nos critérios de pontuação utilizados pelo programa analisado para processos de seleção de mestrandos e doutorandos, como no próprio fato de haver uma menor dedicação dos docentes para as atividades de extensão. Nesse sentido, cabe uma reflexão de que a extensão possa viabilizar menor capital simbólico do que os outros tipos de atividades, ressaltando, contudo, o fato de estarmos tratando do contexto de um programa de pós-graduação Stricto-Sensu, que está submetido a vários objetivos e regras de produtividade acadêmica. Ainda assim, cabe uma reflexão a esse respeito, já que o conceito de universidade é construído pelo tripé ensino, pesquisa e extensão.

As limitações do estudo são a utilização, como objeto de análise, de um único programa Stricto-Sensu, o que compromete a possibilidade de generalização dos resultados; e a utilização da teoria de um único autor para embasar as análises realizadas 7 . Deixa-se como sugestão para futuros estudos a ampliação do objeto de estudo e, em termos metodológicos, que os docentes sejam ouvidos por meio de entrevistas, para que seus relatos e discursos sobre as atividades e estratégias que desenvolvem e sobre o modo como percebem o campo científico possam ser agregados às reflexões realizadas. No caso específico deste artigo, a ampliação do recorte de análise com essas entrevistas teria a exposição de seus resultados limitada por questões de espaço.

No entanto, mesmo com tais limitações, acredita-se que o estudo possa contribuir, de forma empírica, para reflexões acerca da complexidade do papel dos docentes de pós-graduação nas universidades públicas brasileiras, uma vez que os mesmos precisam se dedicar a atividades de diferentes naturezas, tendo seu desempenho constantemente avaliado; e acerca do modo como se dá a distribuição de poderes entre tais docentes, o que pode levar a um melhor entendimento das estratégias por eles empreendidas dentro da universidade, já que dependem "de sua reputação junto aos colegas para obter fundos para pesquisa, atrair estudantes de qualidade, conseguir subvenções e bolsas,

7 Embora aqui não estejamos utilizando todos os principais conceitos de Bourdieu (como campo, capital, habitus, doxa, nomos, illusio e hexis). O recorte utilizado e os procedimentos metodológicos adotados não permitem a apreensão de todos estes conceitos no campo estudado. Assim, optou-se no estudo pela abordagem apenas daqueles diretamente relacionados aos objetivos e métodos da pesquisa. 
convites, consultas, distinções"8 (BOURDIEU, 2003), o que se observou no estudo, pois há um processo de alimentação e de realimentação de atividades que propiciam aos pesquisadores a acumulação de capitais no campo.

\section{REFERÊNCIAS}

ARAÚJO, Uajará Pessoa. Relação agência e estrutura em redes colaborativas: uma análise do Consórcio Brasileiro de Pesquisa e Desenvolvimento do Café. 2008. 268 p. Tese (Doutorado) - Universidade Federal de Lavras, Lavras, 2008.

BARBOSA, Solange de Lima et al. Avaliação da eficiência docente em um programa de pós-graduação Stricto-Sensu na região Sul do Brasil com o uso de Data Envelopment Analysis - DEA. In: EnANPAD - Encontro Nacional da ANPAD, 31., 2007, Rio de Janeiro. Anais... Rio de Janeiro: ANPAD, 2007.

BOURDIEU, Pierre. Coisas ditas. São Paulo: Brasiliense, 2004a.

. O campo científico. In: ORTIZ, R. A sociologia de Pierre

Bourdieu. São Paulo: Olho D’água, 2003.

. O poder simbólico. Lisboa: Difel, 1989.

. Os usos sociais da ciência: por uma sociologia clínica do campo científico. São Paulo: UNESP, 2004b.

. Questoes de sociologia. Portugal: Fim de Seculo, 2004c.

. Razões práticas: sobre a teoria da ação. São Paulo: Papirus, 1996.

BRANDÃO, Zaia. Operando com conceitos: com e para além de Bourdieu. Educação e Pesquisa, São Paulo, v. 36, n. 1, p. 227-241, 2010.

BRASIL. Decreto n. 3.860, de 9 de julho de 2001. Diário Oficial [da] República Federativa do Brasil, Brasília, DF, 10 jul. 2001.

. Lei n. 9.394, de 20 de dezembro de 1996. Brasília, DF, 20 dez.

\section{6.}

8 Sugere-se para futuras pesquisas, nesse sentido, uma análise da acumulação pelos docentes de capital social, que pode ser representado pela rede de relações que ele constrói no campo. Uma ferramenta interessante para esta análise é a chamada "redes de colaboração", que está disponível na Plataforma Lattes, demonstrando a rede de colaboração em pesquisas e projetos construída pelo pesquisador. 
CHAUI, Marilena. A universidade pública sob nova perspectiva. Revista Brasileira de Educação, Rio de Janeiro, n. 24, set./out./nov./dez. 2003. COORDENAÇÃO DE APERFEIÇOAMENTO DE PESSOAL DE NÍVEL SUPERIOR (CAPES). Qualis Periódicos. 2011. Disponível em: <www. capes.gov.br>. Acesso em: 24 jul. 2011.

. Sobre a Capes. 2010. Disponível em: <www.capes.gov.br>. Acesso em: 20 jun. 2010.

DUARTE JUNIOR, João Francisco. O que é realidade. 10. ed. São Paulo: Brasiliense, 1986.

FREITAG, Michel. Le naufrage de l'université. Paris: Editions de La Découverte, 1996.

GIL, Antônio Carlos. Métodos e técnicas de pesquisa social. 5. ed. São Paulo: Atlas, 1999.

GODOY, Arilda Schmidt. Introdução à pesquisa qualitativa e suas possibilidades. Revista de Administração de Empresas, São Paulo, v. 35, n.3, p. 20-29, maio/jun. 1995.

MACCARI, Emerson Antônio et al. Sistema de avaliação da pósgraduação da Capes: pesquisa-ação em um programa de Pós-Graduação em Administração. Revista Brasileira de Pós-Graduação, Brasília, v. 5, n. 9, p. 171-205, dez. 2008.

MIRANDA, Caroline Maria Guerra de; ALMEIDA, Adiel Teixeira de. Visão multicritério da avaliação de programas de pós-graduação pela CAPES: o caso da área Engenharia III baseado nos métodos Electre II e MAUT. Gestão \& Produção, São Carlos, v. 11, n. 1, p. 51-64, jan./abr. 2004.

MISOCZKY, Maria Ceci Araújo. Implicações do uso das formulações sobre campo de poder e ação de Bourdieu nos estudos organizacionais. Revista de Administração Contemporânea, Curitiba, edição especial, p. 9-30, 2003.

RICHARDSON, Roberto Jarry. Pesquisa Social: métodos e técnicas. 3. ed. São Paulo: Atlas, 1999.

ROWE, Diva Ester Okazaki; BASTOS, Antônio Virgílio Bittencourt. Comprometimento ou entricheiramento na carreira? Um estudo entre docentes do ensino superior. In: EnANPAD - Encontro Nacional da ANPAD, 32., 2008, Rio de Janeiro. Anais... Rio de Janeiro: ANPAD, 2008. 
SCOTT, W. Richard. Institutions and organizations. London: Sage, 2001.

SETTON, Maria da Graça Jacintho. A teoria do habitus em Pierre Bourdieu: uma leitura contemporânea. Revista Brasileira de Educação, Rio de Janeiro, n. 20, p. 60-70, maio/jun./ago. 2002.

SIMÕES, Regina Helena Silva. Da avaliação da educação à educação da avaliação: o lugar do(a) educador(a) no processo da avaliação da PósGraduação no Brasil. Psicologia e Sociedade, Belo Horizonte, v. 16, n. especial, 2004, p. 124-134.

SOUSA SANTOS, Boaventura de. A universidade no século XXI: para uma reforma democrática e emancipatória da universidade. Educação, Sociedade e Culturas, Porto, n. 23, 2005.

SPAGNOLLO, Fernando; SOUZA, Valdinei Costa. O que mudar na Avaliação Capes? Revista Brasileira de Pós-Graduação, Brasília, v. 1, n. 2 , p. 8-34, nov. 2004.

TEIXEIRA, Juliana Cristina. Dinâmica do campo científico e os capitais em jogo na pesquisa em uma universidade pública. 2011. 198 p.

Dissertação (Mestrado em Administração) - Universidade Federal de Lavras, Lavras, 2011.

THIRY-CHERQUES, H. R. Pierre Bourdieu: a teoria na prática. Revista de Administração Pública, Rio de Janeiro, v. 40, n. 1, p. 27-55, jan./fev. 2006.

VANDERLEY, Luciano Gonzaga; XIMENES, Lorena Coelho. As facetas da personalidade no entrelinhamento do estresse ocupacional dos docentes do curso de Administração. In: EnANPAD - Encontro Nacional da ANPAD, 32., 2008, Rio de Janeiro. Anais... Rio de Janeiro: ANPAD, 2008.

VARGAS, Lilia. Guia para a apresentação de trabalhos científicos. Porto Alegre: UFRGS, 2001.

VICENTIN, Flávia Oliveira do Prado; PASSADOR, João Luiz. Análise institucional: um estudo dos programas de pós-graduação Stricto Sensu da Faculdade de Medicina de Ribeirão Preto/USP. In: EnANPAD - Encontro Nacional da ANPAD, 32., 2008, Rio de Janeiro. Anais... Rio de Janeiro: ANPAD, 2008. 